\title{
Combination of biochar and immobilized bacteria in cypermethrin-contaminated soil remediation
}

Jie Liu ${ }^{\mathrm{a}, \mathrm{b}}$, Yanli Dinga ${ }^{\mathrm{a} \#}$, Lili Ma ${ }^{\mathrm{a}, \mathrm{c}}$, Guanghai Gao ${ }^{\mathrm{a}}$, Yingying Wanga* 


\begin{abstract}
Cypermethrin is widely applied in agriculture practice and leads to serious soil contamination. Limited information is available on the bioremediation of cypermethrin-contaminated soil using biochar as a carrier for bacteria. In the present study, cypermethrin-degrading bacterial consortium immobilized on biochar was applied to cypermethrin contaminated soil (final content of biochar in soil was $0.5 \%$, $1 \%$ and $2 \%$ respectively) in pot experiments. The results demonstrated that cypermethrin degradation $\left(30 \mathrm{mg} \cdot \mathrm{kg}^{-1}\right)$ in soil fitted the first order kinetic model. The treatment of biochar $(0.5 \%)$ with immobilized bacteria achieved the maximum specific degradation rate constant $\left(0.0422 \mathrm{~d}^{-1}\right)$ and removal rate $(82.18 \%)$ of cypermethrin within 40 days, and shortest degradation half-life of cypermethrin (16.4 d) among all treatments. Furthermore, the results suggested that the biochar addition reduced the bioavailability of cypermethrin to bacteria and cypermethrin removal rate in soil. Two-way ANOVA analysis showed that promoting effect of bacterial consortium addition was stronger than that of biochar in sterilized soil, while biochar had more significant effect than bacteria in natural soil.
\end{abstract}

Key words: cypermethrin; soil remediation; biochar; immobilized bacterial consortium; kinetics 


\section{Introduction}

Since the restricted usage of high toxic organophosphate and organochlorine pesticides, pyrethroids cypermethrin $\left(\mathrm{C}_{22} \mathrm{H}_{19} \mathrm{C}_{12} \mathrm{NO}_{3}\right)$ has been excessively applied in agriculture as a substitute (McCoy et al., 2012; $\underline{\text { Sundaram et al., 2013; }}$ Tiwary and Dubey, 2016). Due to its photostability and thermostability, cypermethrin was very persistent and had long half-life (94.2-1103.0 d) in natural environments (Chen et al., $\underline{2012 \mathrm{~b}}$ ), which led to the accumulation of cypermethrin in soil (Shafer et al., 2005). It was reported that cypermethrin had high acute toxicity to worms. For example, the 96 hours $\mathrm{LC}_{50}$ values of aqueous cypermethrin reached $71.12 \mu \mathrm{g} \cdot \mathrm{L}^{-1}$ for the oligochaete

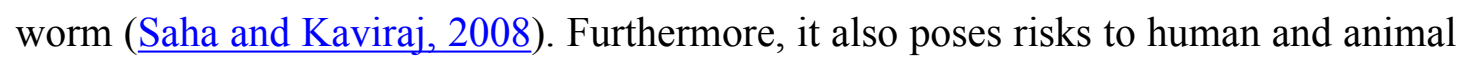
health, including neurovirulence, reproductive toxicity, genotoxicity and carcinogenicity (Shafer et al., 2005; Chen et al., 2012c; Liu et al., 2014). Recently, residual pyrethroids pesticides were detected in agricultural and sideline products (Liu et al., 2014). Therefore, it is critical to exploit a rapid and efficient method to eliminate cypermethrin from the environments.

Microbial biodegradation is one of the key solutions for the bioremediation of cypermethrin contaminated soil. However, the cypermethrin degrading ability of indigenous microorganism is very limited in natural ecosystem (McCoy et al., 2012; Liu et al., 2014). To improve the bioremediation efficiency, addition of exogenous microbial agents or ameliorants was considered as a practicable method (Cai et al., 2010). Previous studies have mainly focused on the isolation of cypermethrin degrading microorganisms. Several cypermethrin-degrading bacteria were identified, including Sphingobium (Guo et al., 2009), Serratia (Zhang et al., 2010a), Rhodococcus (Akbar et al., 2015b), Pseudomonas (Saikia et al., 2005), Bacillus 
(Sundaram et al., 2013; Akbar et al., 2015a; Tiwary and Dubey, 2016), Streptomyces (Chen et al., 2012b; Chen et al., 2012c), Aspergillus, Candida, Cladosporium, Trichoderma (Cycon and Piotrowska-Seget, 2016) and Fusarium (Kaur et al., 2015). For instance, Chen and co-workers isolated a Streptomyces strain which could degrade more than $80 \%$ of beta-cypermethrin $\left(50 \mathrm{mg} \cdot \mathrm{kg}^{-1}\right)$ in soil within ten days (Chen et al., 2012b). In practice, the bioremediation efficiency not only depended on the degradation ability of microbes and environmental conditions (salinity, nutrient, $\mathrm{pH}$ and temperature etc.) in polluted soil (Cycon and Piotrowska-Seget, 2016), but also on the bioavailability of pollutants and the interaction between exogenous and indigenous microorganisms (El Fantroussi and Agathos, 2005; Llado et al., 2013). To improve the bioremediation efficiency of exogenous microorganisms, immobilization of exogenous degradation microbes onto carriers was proposed as a perspective

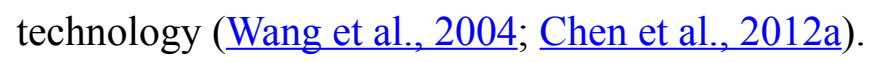

As an important soil ameliorant, biochar has great potential for addressing many important global issues, such as energy dilemma, climate change (Meyer et al., 2011), agricultural production (Atkinson et al., 2010) and environmental problems (Qin et al., 2013; Cernansky, 2015; Wang et al., 2016). It has been reported that biochar addition to soil could improve the soil adsorption capacity to pesticides and promote microbial growth (Uchimiya et al., 2012; Cabrera et al., 2014; Trigo et al., 2014; Eibisch et al., 2015). Furthermore, biochar could catalyze the reductive reactions of herbicides ( $\underline{\mathrm{Oh} \text { et al., 2013 }}$ ). However, to the best of our knowledge, there is very limited information on using biochar as a carrier for bacteria in bioremediation, especially for cypermethrin-contaminated soil. In the present study, the bacterial consortium isolated from our previous work was acclimated and immobilized on 
biochar, and pot experiments were carried out to investigate their bioremediation efficiency in cypermethrin-contaminated soil. 


\section{Materials and Methods}

\subsection{Acclimatization and enrichment of bacterial consortium}

The mineral salt medium (MSM) was consisted of the following chemicals $\left(\mathrm{g} \cdot \mathrm{L}^{-1}\right): \mathrm{NH}_{4} \mathrm{NO}_{3} 1.0, \mathrm{MgSO}_{4} \cdot 7 \mathrm{H}_{2} \mathrm{O} \quad 0.5,\left(\mathrm{NH}_{4}\right)_{2} \mathrm{SO}_{4} 0.5, \mathrm{KH}_{2} \mathrm{PO}_{4} 0.5, \mathrm{NaCl} 0.5$ and $\mathrm{K}_{2} \mathrm{HPO}_{4}$ 1.5, and trace elements $\left(5 \mathrm{~mL} \cdot \mathrm{L}^{-1}\right)$. Trace elements contained $\left(\mathrm{g} \cdot \mathrm{L}^{-1}\right)$ $\left(\mathrm{NH}_{4}\right)_{6} \mathrm{Mo}_{7} \mathrm{O}_{24} \cdot 4 \mathrm{H}_{2} \mathrm{O} 1.0, \mathrm{ZnSO}_{4} \cdot 7 \mathrm{H}_{2} \mathrm{O} 3.0, \mathrm{CoSO}_{4} \cdot 7 \mathrm{H}_{2} \mathrm{O} 3.0, \mathrm{MnSO}_{4} \cdot 2 \mathrm{H}_{2} \mathrm{O} 2.0$ and $\mathrm{CuSO}_{4} \cdot 5 \mathrm{H}_{2} \mathrm{O} 5.0$.

The bacterial consortium, consisting of Bacillus Zhanjiangensis strain TJTB48, Bacillus Pseudofirmus TJTB58 and Oceanobacillus kimchii TJTB66, used in the present study was isolated from our previous study (Feng et al., 2013). The enrichment medium contained $100 \mathrm{~mL}$ MSM in a $250 \mathrm{~mL}$ Erlenmeyer flask with a final concentration of $30 \mathrm{mg} \cdot \mathrm{L}^{-1}$ cypermethrin as the sole carbon and energy source. The culture was incubated in an incubator shaker at $30{ }^{\circ} \mathrm{C}$ and kept in dark. The culture was transferred approximately once a week on the basis of depletion (more than $85 \%$ ) of the substrate. At each transfer, $10 \mathrm{~mL}$ of the culture was transferred to a new flask containing $90 \mathrm{~mL}$ freshly prepared MSM with the $30 \mathrm{mg} \cdot \mathrm{L}^{-1}$ of cypermethrin. The acclimated culture was transferred more than 4 times prior application in the pot experiments.

Bacterial concentration was measured by flow cytometry (FCM) following previously reported protocol (Ma et al., 2013). Bacterial culture was stained with 10 $\mu \mathrm{L} \cdot \mathrm{mL}^{-1}$ SYBR Green I (1:100 dilution in dimethylsulfoxide; Invitrogen, USA), and incubated in the dark for $15 \mathrm{~min}$ at room temperature before measurement. The specific instrumental gain settings for measurements were as follows: FL1 $=220$, FL3 $=180, \mathrm{SSC}=180$. When necessary, samples were diluted before measurement in cell- 
free water, so that the concentration measured by FCM was always less than $2 \times 10^{5}$ cells $\cdot \mathrm{mL}^{-1}$. Samples were measured in triplicate. The detection limit of the instrument used in present study was about 200 cells $\cdot \mathrm{mL}^{-1}$ (Liu et al., 2016).

\subsection{Pot experiments for cypermethrin-contaminated soil remediation with} biochar and immobilized bacteria

The acclimated bacterial consortium was cultured in MSM adding $1 \%(\mathrm{v} / \mathrm{v})$ Lysogeny Broth (LB) medium and incubated at $150 \mathrm{r} \cdot \mathrm{min}^{-1}$ and $30{ }^{\circ} \mathrm{C}$ for $48 \mathrm{~h}$. LB medium was consisted of peptone $10.0 \mathrm{~g} \cdot \mathrm{L}^{-1}$, yeast extract $5.0 \mathrm{~g} \cdot \mathrm{L}^{-1}$ and $\mathrm{NaCl} 10.0$ $\mathrm{g} \cdot \mathrm{L}^{-1}$. Biochar was obtained from maize straw, which was pyrolysed at $600{ }^{\circ} \mathrm{C}$ for $1 \mathrm{~h}$. Biochar was then added to the acclimated consortium culture at the percentage of $0.5 \%, 1 \%$ and $2 \%\left(\mathrm{~W}_{\text {biochar }} / \mathrm{V}_{\text {medium }}\right)$, respectively. The mixture was incubated for $24 \mathrm{~h}$.

Soil samples was collected from the top layer $(5-20 \mathrm{~cm})$ of a farmland in Tianjin, China, then weathered and screened through a 2-mm sieve. The sterile soil was obtained by autoclaving at $120{ }^{\circ} \mathrm{C}$ for $60 \mathrm{~min}$. The sterilization process was repeated three times.

Pot experimental design was shown in Table 1. The experiments were carried out in a greenhouse. Each treatment had three replicates. Bacterial consortium immobilized on the biochar or biochar alone was added to the sterile and natural soil at the concentration of $100 \mathrm{~mL} \cdot \mathrm{kg}^{-1}$ (the final content of biochar was $0.5 \%, 1 \%$ and $2 \%$ in soil). Negative controls (i.e. no biochar or bacteria addition) were set for both sterile and natural soil. Cypermethrin dissolved in acetonitrile was added to each pot with a final concentration of $30 \mathrm{mg} \cdot \mathrm{kg}^{-1}$. All the pots were watered regularly to keep $40 \%$ of the water holding capacity by adding Milli-Q water. Fifty gram soil was taken 
from each pot at the $1^{\text {st }}, 10^{\text {th }}, 20^{\text {th }}, 30^{\text {th }}$ and $40^{\text {th }}$ day. Each soil sample was analyzed in triplicate.

\subsection{Cypermethrin quantification}

$10 \mathrm{~mL}$ petroleum ether and $20 \mathrm{~mL}$ acetonitrile was added to $10 \mathrm{~g}$ soil in $100 \mathrm{~mL}$ glass flask, and mixed at $200 \mathrm{r} \cdot \mathrm{min}^{-1}$ for $1 \mathrm{~h}$, followed by ultrasonication for $30 \mathrm{~min}$. After adding anhydrous sodium sulfate and incubating at room temperature for $2 \mathrm{~h}, 10$ $\mathrm{mL}$ suspension was collected and passed through $0.45 \mu \mathrm{m}$ pore-sized nylon (PA) membrane. Solid phase extraction (SPE) columns (CNWBOND Alumina-N, ANPEL, China) was applied for cypermethrin extraction. The extraction procedures were as follows: 1) adding $5 \mathrm{~mL}$-hexane and $5 \mathrm{~mL}$ dichloromethane to activate and balance column for $10 \mathrm{~min}$; 2) pumping extraction solvent through the column with controlled flow rate; 3) rinsing the columns with $5 \mathrm{~mL}$ Milli-Q water; 4) eluting the column with $10 \mathrm{~mL}$ dichloromethane. The same SPE condition was applied to cypermethrin external standards. Cypermethrin was quantified by GC-MS (Thermo DSQII, Agilent), which was a Agilent Technologies 5975C gas chromatograph equipped with a Agilent Technologies 7890A Mass Spectrometer. Chromatographic column applied was an Eclipse HP-5MS $(30 \mathrm{~m} \times 0.25 \mathrm{~mm} \times 0.25 \mu \mathrm{m})$ column purchased from Agilent. The operating conditions were set based on a previously reported method (Chen et al., 2012b). The column was held initially at $100{ }^{\circ} \mathrm{C}$ for $1 \mathrm{~min}$, then raised at $30{ }^{\circ} \mathrm{C} \cdot \mathrm{min}^{-1}$ to $190{ }^{\circ} \mathrm{C}$ for $1 \mathrm{~min}$, at $8{ }^{\circ} \mathrm{C} \cdot \mathrm{min}^{-1}$ to $300{ }^{\circ} \mathrm{C}$ for $5 \mathrm{~min}$. The temperatures corresponding to the transfer line and the ion trap were $150{ }^{\circ} \mathrm{C}$ and $230{ }^{\circ} \mathrm{C}$, respectively. The ionization energy was $70 \mathrm{eV}$. The injection volume was $1.0 \mu \mathrm{L}$ with splitless sampling at $280{ }^{\circ} \mathrm{C}$. Helium $(99.999 \%)$ was used as the carrier gas at a flow 
rate of $1.0 \mathrm{~mL} \cdot \mathrm{min}^{-1}$.

\subsection{Statistical analysis}

Changes of residual cypermethrin in soil was fitted by first-order kinetics model $\left(C_{t}=\right.$ $\left.C_{0} \mathrm{e}^{-k t}\right) . C_{0}$ represents the amount of substrate at time zero, and $C_{t}$ represents the amount of substrate at time $t . k$ and $t$ are the removal rate constant and degradation period, respectively. The cypermethrin concentration was converted by logarithm for the removal rate constant calculation. The slope value $(k)$ in the model represented the removal rate constant of cypermethrin in bioremediation, and the half-life $\left(T_{1 / 2}\right)$ value of cypermethrin was calculated by following equation: $T_{1 / 2}=\ln 2 / k$. The two-way ANOVA was performed to compare the bioremediation efficiency of biochar with or without immobilized bacterial consortium in natural and sterile soil. 


\section{Results and Discussion}

\subsection{Bacterial growth during acclimatization}

In the initial period $(74 \mathrm{~h})$ of the acclimation, the consortium was in adaptive lag phase and no obvious growth was detected. The bacterial concentration was kept at $1.4 \times 10^{5}$ cells $\cdot \mathrm{mL}^{-1}$ (Figure 1). Cypermethrin has high molecular weight and complex chemical structure such as ester bond and phenyl ring (Cycon and Piotrowska-Seget, 2016). Hence it is not readily usable by the bacteria and may also inhibit their metabolic activity which leads to the long lag phase. Such extended lag phase was also observed previously with the increasing of initial concentrations of cypermethrin (Dubey and Fulekar, 2013). Inducible cypermethrin-degrading enzymes and the essential catabolic esterase (e.g. carboxylesterase and serine esterases, phenol hydroxylase, and dioxygenase) were readily synthesized after the acclimatization period (Saikia et al., 2005; Akbar et al., 2015a; Xiao et al., 2015), which enabled the bacterial consortium to propagate rapidly. It was observed that the culture began the logarithmic growth after $74 \mathrm{~h}$ and reached stationary phase with a final bacterial concentration of $1.3 \times 10^{7}$ cells $\cdot \mathrm{mL}^{-1}$ (Figure 1$)$.

\subsection{Remediation kinetics}

The results showed that combining biochar and bacterial consortium could efficiently remediate cypermethrin-contaminated soil (Figure 2). Although cypermethrin concentration was slightly decreased in both the sterilized and natural blank control, residual cypermethrin in treatment groups was significantly lower than that of blank controls after 40 days $(P<0.001)$. Dynamics model used to fit the changes of residual cypermethrin with time indicated that degradation process 
followed the first-order kinetics in both treatment and blank groups (Figure 2). The results were consistent with a previous study where Akbar and coworkers found that cypermethrin degradation $\left(200 \mathrm{mg} \cdot \mathrm{kg}^{-1}\right)$ in aquatic environments by Acinetobacter calcoaceticus, Brevibacillus parabrevis, and Sphingomonas fitted the first-order kinetics with degradation rate constants of $0.0406,0.0722$, and $0.0483 \mathrm{~d}^{-1}$ respectively (Akbar et al., 2015a). Chen and colleagues investigated degradation characteristics and kinetics of pyrethroid by Streptomyces sp. HP-S-01, which could effectively degrade beta-cypermethrin $\left(50 \mathrm{mg} \cdot \mathrm{kg}^{-1}\right)$ with degradation rates of $80.5 \%$ and $87.8 \%$ within 10 days in sterilized and non-sterilized soils, respectively. The degradation reaction also followed first-order kinetics (hen et al., 2012b). Furthermore, an earlier report indicated that natural degradation processes of dimethyl phthalate (DMP) in soil with biochar also fitted the first-order kinetics equation (Zhou et al., 2014).

The removal rate constant $(k)$ and half-life $\left(T_{1 / 2}\right)$ of cypermethrin were calculated using the first-order model equation. Kinetics model displayed that cypermethrin could be removed to certain extent in the natural and sterilized blank control (Figure 2 and Figure 3). The cypermethrin removal rate constants and half-life were $0.0067 \mathrm{~d}^{-1}$ (removal rate, $24.76 \%$ ) and $0.0059 \mathrm{~d}^{-1}$ (removal rate, $19.42 \%$ ), and $103.4 \mathrm{~d}$ and 117.5 $\mathrm{d}$ in natural and sterilized blank control, respectively. There was no significant difference between the natural and sterile blank control groups $(P>0.05)$. The results indicated that indigenous microorganisms had very limited contribution to the cypermethrin degradation in soil, and abiotic degradation (e.g. photolysis, hydrolyzation and redox) was the main pathway to eliminate the cypermethrin in the natural environments (Pei and Luan, 2012; Akbar et al., 2015a). It was reported that chromophore in pyrethroids could absorb the visible and ultraviolet light and the light 
energy absorption would cause photochemical reaction which can oxidize pyrethroids to epoxide, alcohol, aldehyde and carboxylic acid (Reddy and Kim, 2015). Besides, cypermethrin in aqueous solution could be removed by irradiation with a high removal rate (i.e. 84\%) (Zhang et al., 2010b). In the present study, half-life of cypermethrin was more than $100 \mathrm{~d}$ in control samples, which demonstrated that cypermethrin was very persistent in soil.

The removal rate constants of treatment groups were significantly higher than that of control groups $(P<0.01)$ (Figure 2 and Figure 3). The highest removal rate in the biochar treatments was observed in A1 where the removal rate was $71.0 \%$ (removal rate constant was $0.0341 \mathrm{~d}^{-1}$ ), and the half-life was $20.3 \mathrm{~d}$. Treatment $\mathrm{C} 1$ ( $0.5 \%$ biochar with immobilized bacteria) had the maximum removal rate $(82.18 \%$ within $40 \mathrm{~d}$ and removal rate constant was $\left.0.0422 \mathrm{~d}^{-1}\right)$ and the shortest half-life (16.4 d) among all treatments. Comparing to the control, the half-life of $\mathrm{C} 1$ treatment was shortened by $84.1 \%$, which indicated that biochar in combination with immobilized bacterial consortium promoted the removal of cypermethrin. It was probably due to the fact that graphite structure in biochar can provide adsorption and redox reaction

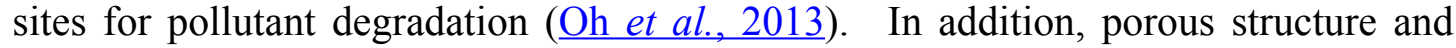
surface properties of biochar could provide a good habitat and nutrient elements for microbial growth and reproduction, and enhance bacterial activity (Lehmann et al., 2011; Ding et al., 2013).

The results revealed that removal rate constant of cypermethrin decreased with the increasing amount of biochar addition (Figure 3). The results suggested that there were dual effects of biochar on the remediation of cypermethrin contaminated soil. Adding biochar could not only positively promote the pollutant degradation, but also 
reduce the bioavailability of cypermethrin to microorganisms. It was reported that biochar could limit bioavailability of simazine and hence decreased the risk of environmental contamination and human exposure (Jones et al., 2011). It was also found that addition of biochar into soil could delay natural degradation of dimethyl phthalate (Zhou et al., 2014). Wen and colleagues observed that char amendment significantly reduced pentachlorophenol bioavailability in contaminated soil (Wen et al., 2009). The addition of biochar in soil could absorb the pesticide, then reduce the cypermethrin bioavailability and accumulation in the food chain (Yang et al., 2006; Loganathan et al., 2009; Yu et al., 2009; Rittenhouse et al., 2014). The reduction of pollutants removal rate caused by excessive addition of biochar would lead to more complex distribution of pollutant and might increase their potential risk in ecosystem (Jones et al., 2011; Yu et al., 2011). Therefore, the amount of biochar used for soil remediation should be carefully evaluated for each application.

\subsection{Comparison of remediation efficiency among different treatments}

The two-way ANOVA analysis was used to compare the remediation efficiency of biochar with or without immobilized bacteria. Our results showed that the biochar and bacteria had different effect on the cypermethrin removal in natural and sterile soil (Table 2). The promotion effect of biochar $(F=62.49, P=0.016)$ was great than that of bacteria $(F=17.91, P=0.052)$ in natural soil. In contrast, the inversed effect was observed in sterile soil, where the promotion effect of bacteria $(F=64.86, P=0.015)$ was great than that of biochar $(F=17.68, P=0.054)$. It could be attributed to the fact that sterilized soil is commonly much more hospitable to exogenous microorganisms than natural soil (El Fantroussi and Agathos, 2005). The external bacteria 
immobilized on the biochar could rapidly adapt to the polluted environment and capitalize on nutrients and cypermethrin, as there was no antagonistic effects or resource competition with native microbiota in the sterilized soil. In contrast, the antagonism and competition interactions between the exogenous (consortium added) and the indigenous bacteria could be intense in the natural soil (Llado et al., 2013). Hence the activity as well as the degradation ability of exogenous bacteria would be restricted. 


\section{Conclusions}

The present study investigated bioremediation of cypermethrin-contaminated soil using the combination of biochar and cypermethrin-degrading bacterial consortium. The results revealed that the removal rate of cypermethrin fitted the first-order kinetics, and the treatment with bacteria immobilized on biochar $\left(0.5 \%\right.$, $\left.\mathrm{W}_{\text {biochar }} / \mathrm{W}_{\text {soil }}\right)$ had the highest removal rate constant $\left(0.0422 \mathrm{~d}^{-1}\right)$ and shortest half-life $(16.4 \mathrm{~d})$. The removal rate of cypermethrin decreased with the increasing of biochar addition due to the reduction of cypermethrin bioavailability. The results also showed that the promotion effect of biochar on cypermethrin removal was greater than that of bacterial consortium in natural soil, while the promotion effect of bacterial consortium was greater than that of biochar in sterilized soil. The present study demonstrated that biochar was a useful tool in bioremediation and provided evidence for effective application of biochar in combination of immobilized bacteria. 


\section{Acknowledgements}

The authors are grateful to the financial support from National Basic Research Program of China (2015CB459000), Ministry of Education Innovation Team Program (ITR 30114), and National Science Foundation China (3071454). 


\section{References}

Akbar, S., Sultan, S., Kertesz, M., 2015a. Determination of cypermethrin degradation potential of soil bacteria along with plant growth-promoting characteristics. Curr. Microbiol. 70, 75-84.

Akbar, S., Sultan, S., Kertesz, M., 2015b. Bacterial community analysis of cypermethrin enrichment cultures and bioremediation of cypermethrin contaminated soils. J. Basic Microbiol. 55, 819-829.

Atkinson, C.J., Fitzgerald, J.D., Hipps, N.A., 2010. Potential mechanisms for achieving agricultural benefits from biochar application to temperate soils: a review. Plant Soil 337, 1-18.

Cabrera, A., Cox, L., Spokas, K., Hermosin, M.C., Cornejo, J., Koskinen, W.C., 2014. Influence of biochar amendments on the sorption-desorption of aminocyclopyrachlor, bentazone and pyraclostrobin pesticides to an agricultural soil. Sci. Total Environ. 470, 438-443.

Cai, Z., Zhou, Q.X., Peng, S.W., Li, K.N., 2010. Promoted biodegradation and microbiological effects of petroleum hydrocarbons by Impatiens balsamina L. with strong endurance. J. Hazard. Mater. 183, $731-737$.

Cernansky, R., 2015. State-of-the-art soil. Nature 517, 258-260.

Chen, B.L., Yuan, M.X., Qian, L.B., 2012a. Enhanced bioremediation of PAH-contaminated soil by immobilized bacteria with plant residue and biochar as carriers. J. Soils Sediments 12, 1350-1359.

Chen, S.H., Geng, P., Xiao, Y., Hu, M.Y., 2012b. Bioremediation of beta-cypermethrin and 3phenoxybenzaldehyde contaminated soils using Streptomyces aureus HP-S-01. Appl. Microbiol. Biotechnol. 94, 505-515.

Chen, S.H., Luo, J.J., Hu, M.Y., Lai, K.P., Geng, P., Huang, H.S., 2012c. Enhancement of cypermethrin degradation by a coculture of Bacillus cereus ZH-3 and Streptomyces aureus HP-S-01. Bioresour. Technol. 110, 97-104.

Cycon, M., Piotrowska-Seget, Z., 2016. Pyrethroid-degrading microorganisms and their potential for the bioremediation of contaminated soils: A review. Front. Microbiol. 7, 1463.

Ding, Y.L., Jie, L., Wang, Y.Y., 2013. Effects of biochar on microbial ecology in agriculture soil: A review. Chinese Journal of Applied Ecology 24, 3311-3317.

Dubey, K.K., Fulekar, M.H., 2013. Investigation of potential rhizospheric isolate for cypermethrin degradation. 3 Biotech 3, 33-43.

Eibisch, N., Schroll, R., Fuss, R., Mikutta, R., Helfrich, M., Flessa, H., 2015. Pyrochars and hydrochars differently alter the sorption of the herbicide isoproturon in an agricultural soil. Chemosphere 119, $155-162$.

El Fantroussi, S., Agathos, S.N., 2005. Is bioaugmentation a feasible strategy for pollutant removal and 
site remediation? Curr. Opin. Microbiol. 8, 268-275.

Feng, W., Sun, R., Gao, G.H., Wang, Y.Y., 2013. Analysis of cultivable microbial community structure and affiliation in saline- alkaline soil in the Tuanbo Lake area of Tianjin, China. Journal of AgroEnvironment Science 32, 1028-1035.

Guo, P., Wang, B., Hang, B., Li, L., Ali, S.W., He, J., Li, S., 2009. Pyrethroid-degrading Sphingobium sp JZ-2 and the purification and characterization of a novel pyrethroid hydrolase. Int. Biodeterior. Biodegrad. 63, 1107-1112.

Jones, D.L., Edwards-Jones, G., Murphy, D.V., 2011. Biochar mediated alterations in herbicide breakdown and leaching in soil. Soil Biology and Biochemistry 43, 804-813.

Kaur, P., Sharma, A., Parihar, L., 2015. In vitro study of mycoremediation of cypermethrincontaminated soils in different regions of Punjab. Ann. Microbiol. 65, 1949-1959.

Lehmann, J., Rillig, M.C., Thies, J., Masiello, C.A., Hockaday, W.C., Crowley, D., 2011. Biochar effects on soil biota-a review. Soil Biology and Biochemistry 43, 1812-1836.

Liu, F.F., Chi, Y.L., Wu, S., Jia, D.Y., Yao, K., 2014. Simultaneous degradation of cypermethrin and its metabolite, 3-phenoxybenzoic acid, by the cooperation of Bacillus licheniformis B-1 and Sphingomonas sp SC-1. J. Agric. Food Chem. 62, 8256-8262.

Liu, J., Hao, Z., Ma, L., Ji, Y., Bartlam, M., Wang, Y., 2016. Spatio-temporal variations of high and low nucleic acid content bacteria in an exorheic river. PLoS ONE 11, e0153678.

Llado, S., Gracia, E., Solanas, A.M., Vinas, M., 2013. Fungal and bacterial microbial community assessment during bioremediation assays in an aged creosote-polluted soil. Soil Biology and Biochemistry 67, 114-123.

Loganathan, V.A., Feng, Y., Sheng, G.D., Clement, T.P., 2009. Crop-residue-derived char influences sorption, desorption and bioavailability of atrazine in soils. Soil Sci. Soc. Am. J. 73, 967-974.

Ma, L.L., Mao, G.N., Liu, J., Yu, H., Gao, G.H., Wang, Y.Y., 2013. Rapid quantification of bacteria and viruses in influent, settled water, activated sludge and effluent from a wastewater treatment plant using flow cytometry. Water Sci. Technol. 68, 1763-1769.

McCoy, M.R., Yang, Z., Fu, X., Ahn, K.C., Gee, S.J., Bom, D.C., Zhong, P., Chang, D., Hammock, B.D., 2012. Monitoring of total type II pyrethroid pesticides in citrus oils and water by converting to a common product 3-phenoxybenzoic acid. J. Agric. Food Chem. 60, 5065-5070.

Meyer, S., Glaser, B., Quicker, P., 2011. Technical, economical, and climate-related aspects of biochar production technologies: A literature review. Environ. Sci. Technol. 45, 9473-9483.

Oh, S.-Y., Son, J.-G., Chiu, P.C., 2013. Biochar-mediated reductive transformation of nitro herbicides 
and explosives. Environ. Toxicol. Chem. 32, 501-508.

Pei, D.H., Luan, J.F., 2012. Development of visible light-responsive sensitized photocatalysts. Int. J. Photoenergy 2012, 1-13.

Qin, G., Gong, D., Fan, M.-Y., 2013. Bioremediation of petroleum-contaminated soil by biostimulation amended with biochar. Int. Biodeterior. Biodegrad. 85, 150-155.

Reddy, P.V.L., Kim, K.-H., 2015. A review of photochemical approaches for the treatment of a wide range of pesticides. J. Hazard. Mater. 285, 325-335.

Rittenhouse, J.L., Rice, P.J., Spokas, K.A., Koskinen, W.C., 2014. Assessing biochar's ability to reduce bioavailability of aminocyclopyrachlor in soils. Environ. Pollut. 189, 92-97.

Saha, S., Kaviraj, A., 2008. Acute toxicity of synthetic pyrethroid cypermethrin to some freshwater organisms. Bull. Environ. Contam. Toxicol. 80, 49-52.

Saikia, N., Das, S.K., Patel, B.K.C., Niwas, R., Singh, A., Gopal, M., 2005. Biodegradation of betacyfluthrin by Pseudomonas stutzeri strain S1. Biodegradation 16, 581-589.

Shafer, T.J., Meyer, D.A., Crofton, K.M., 2005. Developmental neurotoxicity of pyrethroid insecticides: Critical review and future research needs. Environ. Health Perspect. 113, 123-136.

Sundaram, S., Das, M.T., Thakur, I.S., 2013. Biodegradation of cypermethrin by Bacillus sp in soil microcosm and in-vitro toxicity evaluation on human cell line. Int. Biodeterior. Biodegrad. 77, 39-44.

Tiwary, M., Dubey, A.K., 2016. Cypermethrin bioremediation in presence of heavy metals by a novel heavy metal tolerant strain, Bacillus sp AKD1. Int. Biodeterior. Biodegrad. 108, 42-47.

Trigo, C., Spokas, K.A., Cox, L., Koskinen, W.C., 2014. Influence of soil biochar aging on sorption of the herbicides MCPA, nicosulfuron, terbuthylazine, indaziflam, and fluoroethyldiaminotriazine. J. Agric. Food Chem. 62, 10855-10860.

Uchimiya, M., Wartelle, L.H., Boddu, V.M., 2012. Sorption of triazine and organophosphorus pesticides on soil and biochar. J. Agric. Food Chem. 60, 2989-2997.

Wang, C., Gu, L., Liu, X., Zhang, X., Cao, L., Hu, X., 2016. Sorption behavior of Cr(VI) on pineapplepeel-derived biochar and the influence of coexisting pyrene. Int. Biodeterior. Biodegrad. 111, 78-84.

Wang, Y., Fan, Y., Gu, J.-D., 2004. Dimethyl phthalate ester degradation by two planktonic and immobilized bacterial consortia. Int. Biodeterior. Biodegrad. 53, 93-101.

Wen, B., Li, R.J., Zhang, S.Z., Shan, X.Q., Fang, J., Xiao, K., Khan, S.U., 2009. Immobilization of pentachlorophenol in soil using carbonaceous material amendments. Environ. Pollut. 157, 968-974.

Xiao, Y., Chen, S., Gao, Y., Hu, W., Hu, M., Zhong, G., 2015. Isolation of a novel beta-cypermethrin degrading strain Bacillus subtilis BSF01 and its biodegradation pathway. Appl. Microbiol. Biotechnol. 
99, 2849-2859.

Yang, Y.N., Sheng, G.Y., Huang, M.S., 2006. Bioavailability of diuron in soil containing wheat-strawderived char. Sci. Total Environ. 354, 170-178.

Yu, X.Y., Ying, G.G., Kookana, R.S., 2009. Reduced plant uptake of pesticides with biochar additions to soil. Chemosphere 76, 665-671.

Yu, X.Y., Mu, C.L., Gu, C., Liu, C., Liu, X.J., 2011. Impact of woodchip biochar amendment on the sorption and dissipation of pesticide acetamiprid in agricultural soils. Chemosphere 85, 1284-1289.

Zhang, C., Jia, L., Wang, S., Qu, J., Li, K., Xu, L., Shi, Y., Yan, Y., 2010a. Biodegradation of betacypermethrin by two Serratia spp. with different cell surface hydrophobicity. Bioresour. Technol. 101, 3423-3429.

Zhang, Q.F., Wang, F., Ha, Y.-M., 2010b. Research on irradiation degradation and products characteristics of chlorpyrifos and cypermethrin. Scientia Agricultura Sinica 43, 1041-1049.

Zhou, Z.F., Zhang, H.G., Wang, Q., 2014. Effect of natural degradation and adsorption of dimethyl phthalate by adding biochar to soil. Chinese Journal of Environmental Engineering 8, 4474-4479. 
Table 1 Experimental design for remediation using biochar (BC) with or without immobilized bacterial consortium (IBC)

\begin{tabular}{cc}
\hline $\begin{array}{c}\text { Treatment } \\
\text { serial }\end{array}$ & Treatment* \\
\hline A1 & $0.5 \%$ BC in natural soil \\
A2 & $1 \%$ BC in natural soil \\
A3 & $2 \%$ BC in natural soil \\
B1 & $0.5 \%$ BC in sterile soil \\
B2 & $1 \%$ BC in sterile soil \\
B3 & $2 \%$ BC in sterile soil \\
C1 & $0.5 \%$ BC with IBC in natural soil \\
C2 & $1 \%$ BC with IBC in natural soil \\
C3 & $2 \%$ BC with IBC in natural soil \\
D1 & $0.5 \%$ BC with IBC in sterile soil \\
D2 & $1 \%$ BC with IBC in sterile soil \\
D3 & $2 \%$ BC with IBC in sterile soil \\
Control & natural soil only \\
1(Bk1) & sterile soil only \\
Control & Bk2)
\end{tabular}


Table 2 Two-way ANOVA analysis of effects of biochar and bacteria on cypermethrin removal rate in natural soil and sterilized soil

\begin{tabular}{cccccccc}
\hline Treatment & $\begin{array}{c}\text { Source } \\
\text { of } \\
\text { variance }\end{array}$ & $\mathrm{SS}\left(\times 10^{-6}\right)$ & df & $\begin{array}{c}\mathrm{MS}\left(\times 10^{-6}\right. \\
)\end{array}$ & $F$ & $P$-value & $F$ crit \\
& Biochar & 377 & 2 & 188 & $\begin{array}{c}62.4 \\
9\end{array}$ & 0.016 & 19.00 \\
Natural soil & Bacteria & 54 & 1 & 54 & $\begin{array}{c}17.9 \\
1\end{array}$ & 0.052 & 18.51 \\
& Error & 6.03 & 2 & 3.01 & & & \\
\hline & Biochar & 69.7 & 2 & 34.9 & 17.6 & 0.054 & 19.00 \\
& & & & & 8 & & \\
Sterile soil & Bacteria & 128 & 1 & 128 & 64.8 & 0.015 & 18.51 \\
& & & & & 6 & & \\
\hline & Error & 3.94 & 2 & 1.97 & & & \\
\hline
\end{tabular}


Figure Legends

Figure 1 Growth curve of the bacterial consortium in the first round of acclimatization. Error bars represent standard deviation from triplicate measurements.

Figure 2 Kinetics fitting curve of cypermethrin removal rate in different treatment. (A) biochar in natural soil, (B) biochar in sterilized soil, (C) bacteria immobilized on biochar in natural soil, (D) bacteria immobilized on biochar in sterilized soil; Bk1, natural soil control; Bk2, sterilized soil control; CC, cypermethrin concentration.

Figure 3 Removal rate constants, half-life (A) and removal rate (B) of cypermethrin in different treatments. Error bars represent standard deviation of triplicate measurements. 


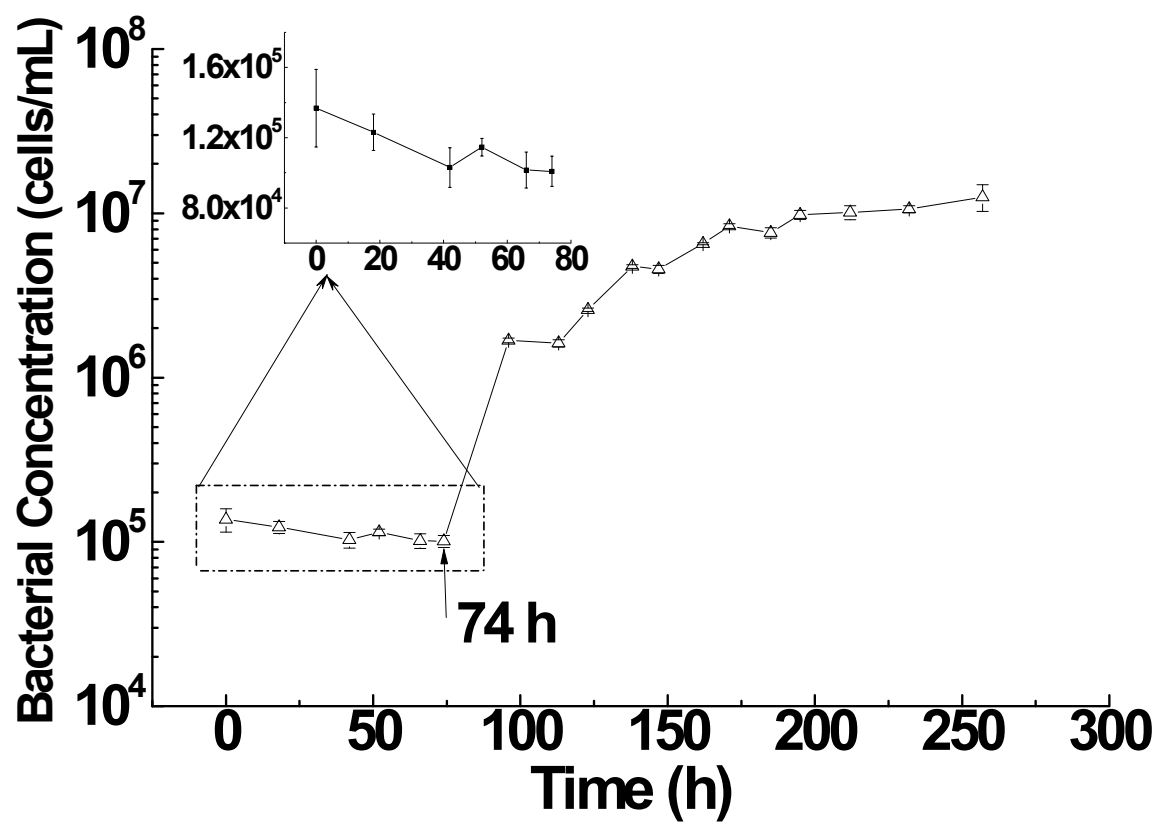

Figure 1 Growth curve of the bacterial consortium in the first round of acclimatization. Error bars represent standard deviation from triplicate measurements. 

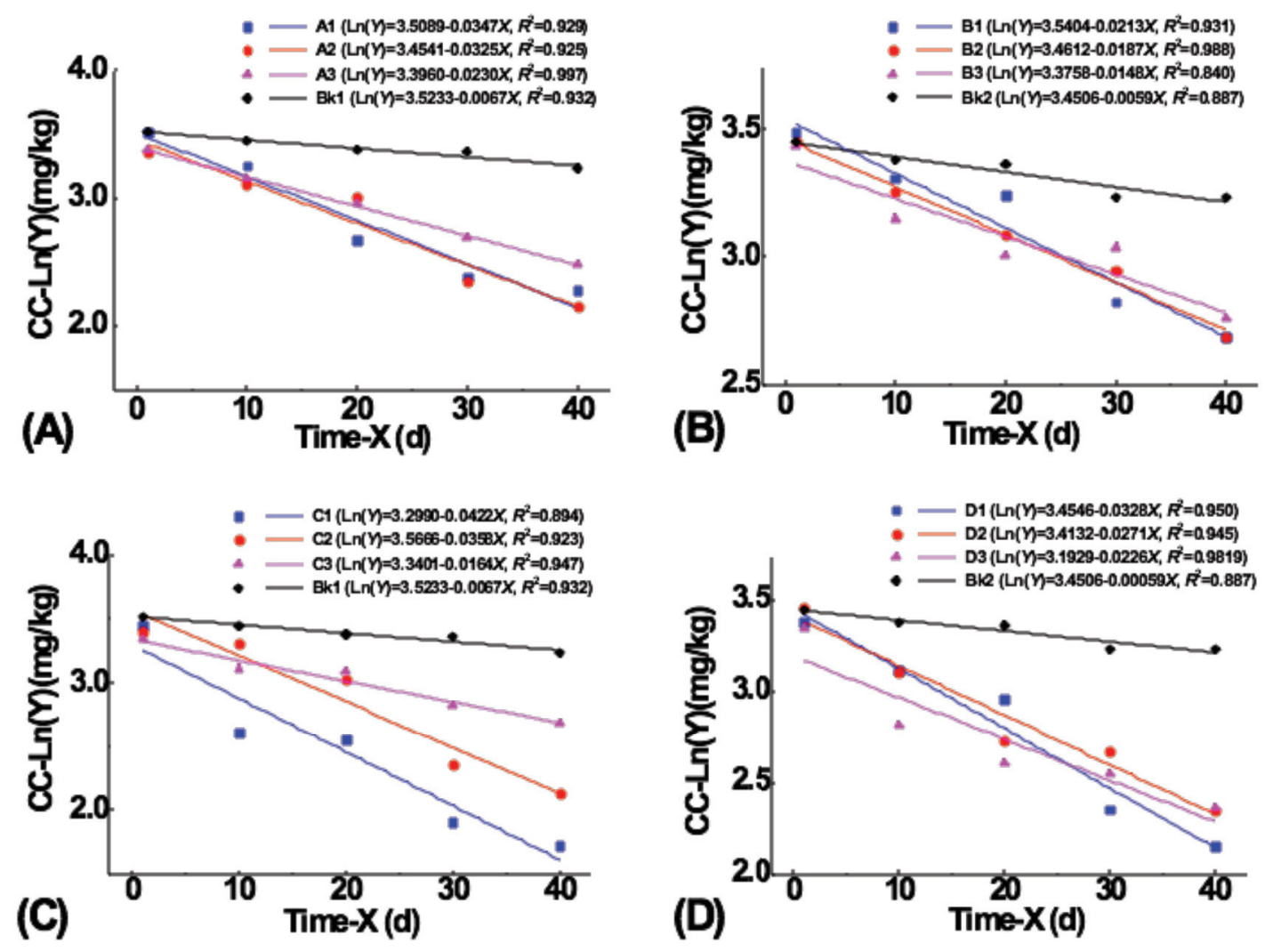

Figure 2 Kinetics fitting curve of cypermethrin removal rate in different treatment. (A) biochar in natural soil, (B) biochar in sterilized soil, (C) bacteria immobilized on biochar in natural soil, (D) bacteria immobilized on biochar in sterilized soil; Bk1, natural soil control; Bk2, sterilized soil control; CC, cypermethrin concentration. 

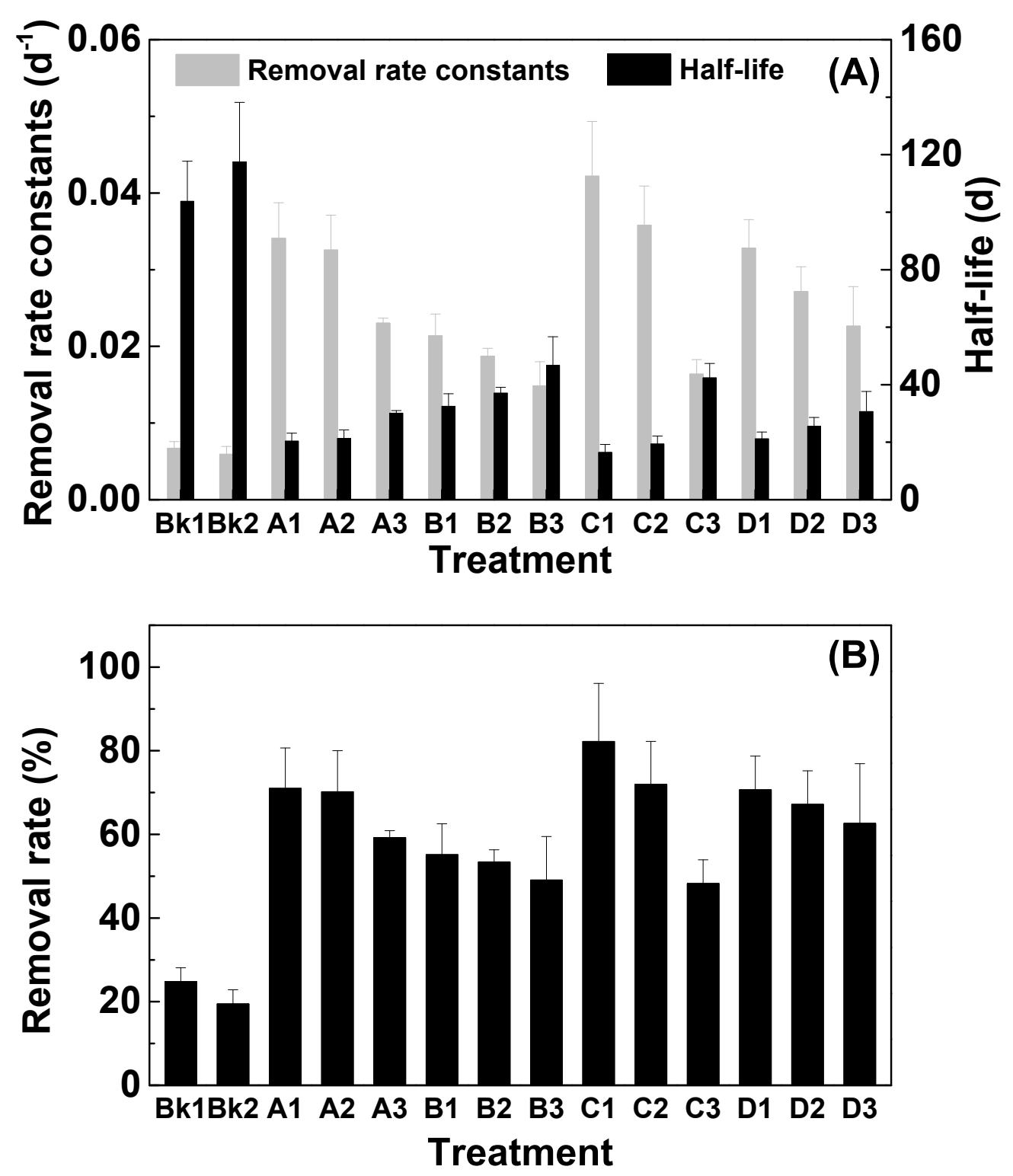

Figure 3 Removal rate constants, half-life (A) and removal rate (B) of cypermethrin in different treatments. Error bars represent standard deviation of triplicate measurements. 